\title{
Realising the strategic value of RFID in academic libraries: A Case Study of the University of Technology Sydney.
}

\author{
John Chelliah, Suresh Sood \& Sally Scholfield
}

\section{Introduction}

The integration of emerging information technology into organised business environments has often been exemplified in libraries; a space that balances unique client needs with highvolume information management requirements. Library information management systems are traditionally high volume and involve repetitive item records management of books and objects for staff with many libraries in the last fifteen years turning from traditional barcodes to RFID technology (Mahajan and Singh 2014; Makori 2013; Bahri and Ibrahim 2013). Radio Frequency Identification Technology, known as RFID, is a form of identification technology that has traditionally found use in machine identification of objects, humans, or animals.

The potential implications for RFID in information management have been explored to a limited degree in academic papers discussing the implications of RFID in machine processes and operational efficiency, but critically evaluated case studies exploring the introduction of RFID into traditional barcode environments and the change management process immanent in the implementation of the technology for improved data management efficiency remains elusive. This paper invites a new perspective on the implementation of RFID in two distinct measures, using a case study of the implementation of RFID technology in the library of the University of Technology Sydney (UTS) to illuminate the change management processes surrounding the nature of an academic (as distinct from a public) library through the introduction of new technology. This approach focuses on the implementation process from a change management perspective rather than a singular assessment of the technological efficacy of the system and focusing on an integrated change management approach combining technology, processes and people (Williams and Leask 2011) to improve knowledge management (Edwards 2011) and performance (Fluss 2005).

The key objectives of the research are to develop a case study that aids management in the library sector to assess the RFID implementation and the associated logistics and change management processes. Through the critical analysis and discussion of key data derived from various participants in the RFID implementation process at the University of Technology Sydney, the research collates the varied perspectives on the benefits, challenges and technological elements involved. 
This study uses the reflections of people in various positions within the academic library management team as well as advisors and other staff members involved in the project such as information technology technicians, to collate perspectives on how key change management principles were involved in the implementation of this technology. This paper uses people, process and technology at the heart of change management as guiding themes.

\section{Theoretical Background}

Radio Frequency Identification Technology (RFID) is a form of identification technology growing in prevalence in the library sector (Smith 2014). The technology has grown significantly due to its capacity to automatically identify objects at a distance without necessitating line-of-sight proximity (Want 2006). RFID, with the inherent potential that it holds for increasing operational efficiency in libraries, holds significant promise for improving the library experience for clients and staff and in terms of overall processing efficiency.

A relatively non-invasive data capture, RFID is 'similar in concept to a cell phone' (Shahid 2005), a dedicated short -range communication classed as 'a wireless link to identify people or objects' (D'Hont, 2003, p. 1, quoted in Wyld 2006, p. 155). A natural partner to the highvolume data management needs of libraries, RFID implementation has grown significantly in the public library sector and relatively slowly in comparison to the rapid adoption of the technology in fields such as retail and defence (Bhattacharya and Chu 2007). As OECD (2008) notes 'this oldest new technology' creates potential for staff to innovate methods for inventory, circulating and tracking library objects that accommodate far higher volume and speed and involve a strong focus on improved library services. The specific implications of RFID implementation include the alleviation of repetitive strain injuries among librarians (Molnar and Wagner 2004), increased security and protection against damage, and protection from misfiling (Brar, Fong and Singh 2006).

The library is a unique environment that blends technological innovation with the sustained need for customer service and highly efficient information management. It has long been an experimental space where emerging technology for patron services are frequently trialled (Bahri and Ibrahim 2013). The following literature review collects several recent publications on the use of RFID in libraries, taking as its focus the change management process around RFID implementation, as well as the effects of RFID implementation on the people, processes and technology indicated in the library environment. This can be explicated further through the key areas of influence of RFID implementation and operation on clients, staff and processes, and the collection of literature herein address in various ways the divergent effect of RFID on these areas. 
The burgeoning role of RFID in library management has stimulated publication of literature on the topic. Bahri and Ibrahim (2013) note a small, but notable, number of academic publications on the implementation of broader categories of emerging IT in libraries. Perhaps the most explored area of emerging technologies was the nature of the implementation process and the question of how to assess the success or challenges of the implementation process at various stages therein (Davey et al. 2011) as well as the nascent area of barriers to implementation in academic libraries. This creates a space for a paper that explores the efficacy and processes of RFID implementation in libraries through the specific organisational principles of change management through the lens of people, technology and processes.

There are several nascent categories of paper on RFID use in libraries. These fall into:

- theoretical discussion papers assessing the state and potentiality of RFID conversion for libraries (Brar, Fong and Singh 2006);

- papers offering assessment of the 'state' of RFID in libraries - a sort of introductory framework to the technology itself (Shahid 2005, Butters 2008);

- papers offering best practice advice and recommendations for RFID usage in libraries, a category which often overlaps with the former discussion papers, for example, in terms of introductory guidelines to RFID usage (Brar, Fong and Singh 2006, Shahid 2005); and

- Papers exploring the privacy concerns, now largely discarded as a result of best practice models, which surrounded RFID implementation initially (Caldwell-Stone 2010, Ferguson 2013, Dewi et al. 2014).

A strong foundation of published case studies has not yet emerged in the field of RFID as a technological foundation for the improvement and development of libraries. As such, the efficacy of RFID implementation and the nature, practice and timeline of implementation processes themselves are not comprehensively documented. In recent years several RFIDbased case studies have been published in various fields, examining implementation in educational institutions (Jain \& Sharma 2014), commercial supply chain settings (Hong et al. 2011; Chen et al. 2013) and in healthcare settings (Southard, Chandra \& Kumar 2012) among others.

At the time of writing, there are limited publications detailing the organisational and innovative potential of RFID technology in libraries (academic, public and private libraries). The papers can be divided into two broad categories. The first of these two categories is a growing body of literature reviews examining the 'use' and/or limitations of RFID (Mahajan \& Singh 2014; Dewi et al 2014; Sing, Brar \& Fong 2013; Dwivedi et al. 2013; Satoglu, Ustundag \& Kilinc 2013). The second category is the growing, albeit limited, field of case studies in RFID implementation in libraries, to which this paper is directed (Jain \& Sharma 2014; Bahri \& Ibrahim 2013; Siguenza-Guzman et al. 2014; Norwood \& Skinner 2012).

\section{The Interplay of People, Processes and Technology}

\section{Insert Figure 1.}

RFID implementation in the UTS library must be analysed in a holistic sense for the case study to truly engage with the multiple factors that played into the objective achievements and efficacy of the technological deployment, seen in Figure 1. The literature creates a clear gap for a case study not only about the efficiency of the RFID technology in the supply chain management process, but also the divergence of expectations of the people, processes and 
technology in the deployment process. Given the consistent issues raised in the literature with the limitations and capacity for human error (Hellstrom and Wiberg 2010, Mehrjedi 2011, Yu 2007), the reality of the RFID deployment distinct from the projected efficiency benefits is a topic warranting attention.

\section{Research Method}

In order to assess the implementation of the RFID system in the University of Technology Sydney Library according to the above principles of change management, a series of interviews were conducted across various participants in the implementation process. The semi-structured questions were accessible to all respondents independent of the variety of qualifications and roles that presented in the sample, and centred on the change management process and the ensuing implications for the people, processes and technology involved in the implementation process.

The decision to undertake a case study as the appropriate methodology for this research comes from the potential of a case study to gather specific, qualitative results from complex and dynamic social phenomena, such as the heterogeneous processes and people involved in the change management process. These results are valuable in that the 'lessons learned' through a case study might be applied to a broader field of social phenomena, for example in structured best practice models or simply as guidelines for decision-making processes. Yin (2014) writes that the case study 'allows investigators to focus on a "case" and retain a holistic and real-world perspective' (Yin 2014, p. 4).

\section{Data Collection}

The collection of data for this research was through the use of semi-structured interviews. Each interview began with a framing question that drew respondents back to the original rationale (in their perception) for the university transition to RFID technology. As the interviews focused on the perceptions of those involved in the implementation process, this broad question initiated the retrospective consideration of the process of implementation and opened a line of inquiry that involved participants assessing the initial rationale, the change management process and visions for the future as well as encouraging a critical assessment of the process as a whole.

Participants were chosen based on their position as the leading participant in their field, for example, IT or library services and relevance to the implementation of RFID technology. Table 1 outlines the positions and relevance of the participants in the structure of the library staff. This decision was made as part of a research design to ensure reliability and academic rigour by engaging respondents that had the expertise, experience and proximal knowledge of the implementation process to provide high quality observations. To best ensure reliability and validity in the collection of data from respondents the publication was produced in collaboration with the UTS library. Staff who had participated checked the data and analysis for accuracy, reliability and academic rigour after which library management gave written approval to publish this paper.

\section{Insert Table 1.}

Informants were provided with the questions in advance allowing adequate preparation with project artefacts (photographs and brochures collected from the participants) encouraged for 
use during the interviews. This technique is adapted from consumer marketing research and known as 'autodriving' (Heisley and Levy 1991) or 'photelicitation' whereby the informants use the artefacts as cues to drive the interview as well as reflect upon the choice of artefacts. The artefacts were essentially photos and brochures collected from the library.

To further develop their narrative of the project, respondents were drawn back towards a 'story' of RFID implementation after being asked about several other aspects of the project. This inquiry, to 'tell us the story', comes from a desire for method, on our part, that goes beyond simple qualitative interviews. It forms a bricolage (Denzin and Lincoln 2005) of multiple qualitative methods, bringing together an ethnography of the academic library postimplementation, together with in-depth interviews with respondents involved in the implementation itself, as well as their volunteered artefacts relating to the project.

The chronology of RFID, as with any technological development, rarely ends with the extant form of implementation and as such respondents were prompted for their visions of the future of RFID in the context of the Library, as well as the wider implications of the technology for the University beyond the Library itself, as well as for the national and international library community.

Each of the interviews were recorded and transcribed, totalling around 8 hours of audio recording. Projected at around sixty minutes each, the interviews ranged from around 30 minutes to more than 60 minutes. The breadth and depth of responses and the time taken in the interviews varied considerably across roles and positioning in the project as respondents engaged with different themes present in the questions.

\section{Data Analysis}

Qualitative research methods involve the use of coding data to generate predominant themes and to achieve data reduction in the preliminary stages of data analysis. To create the coding necessary to develop the transcribed interview documents into structured data, a model was developed involving three major parent nodes: people, processes, and technology, and three free nodes: outside suppliers, innovation capacity and visions for the future.

From the three major parent nodes the data for this particular analysis was coded into several sub-categories that explored the perceptions, expectations and reality of the change management process around the implementation of RFID. To best organise responses, within the major parent nodes of people, processes, and technology, information was coded according to relevance in categories such as expectations before and after implementation, projected and actual outcomes for people, processes and technology, the operation and efficacy of change management, and so forth.

In the analysis of the data that was coded along these lines, there was a secondary line of inquiry that traced the issues surrounding RFID implementation as an emerging information technology in an academic library. A conceptual framework around the responses that assessed the implementation process in terms of the positive and negative decisions made as well as the barriers implicit in the implementation process was developed to best assess the attitudes of the respondents. 
Our conceptual model (Figure 2 below) is based on that used by Azevedo and Carvalho (2011) in their assessment of the contribution of RFID technology to management of fashion supply chains.

\section{Insert Figure 2.}

\section{Findings and Discussion}

The introduction of a technology such as RFID creates a chain reaction that alters processes through which people (includes employees and patrons) interact in the library. The introduction of new technologies to achieve efficiency gains seems to be a major driver in the psyche of management. Employees on the other hand, seem to focus on how the change affects their role and how they execute their daily tasks. RFID technology beyond doubt decreases the need for labour intensive work but it has far reaching consequences including business processes that impact client services. The findings that follow explicate this change process.

\section{People}

There was, across the board, a consensus on a need for change in the methods used in the information management of the library. The need for RFID was articulated most commonly in reference to the projected outcomes of the implementation process. These were varied, often dependent on the relevance of RFID for the individual, and respondents' answers are listed herein:

- RFID offered increased security for library materials in comparison to the destructible nature of traditional barcodes. RFID tags can be read even when they are not directly within the scanner's line of sight unlike barcodes.

- The capacity of RFID to encode more than simple identification information and loan frequency offered an increased potential for monitoring activity and movement within the library building. One respondent noted the capacity of RFID to provide information about 'how and where' books were being used in the library, generating data that could be used in developing discipline and activityoriented areas within the library so as better to use the space. This speaks directly to the work of Sugie (2013) who noted through case-study the potential of RFID technology to "provide... sufficiently accurate data to illustrate and analyze library users' information-seeking behaviors... [providing] more accurate data than traditional research methods, with less effort.' (Sugie 2013, p. 76)

- The improved data collection capacity of RFID was again referred to in the context of the Library facilities transitioning to an automated library retrieval system (LRS) in which less physical space is required to house the materials and an increased need for correct and current data management.

- Multiple references were made to the perceived speed of checkout and keeping collections in order afforded by the implementation of RFID both in the capacity 
for self-service (returns, checkouts, item location) and the effects this would have on library staff and their availability for other tasks.

- The reduced load on library staff in the indexing of stock both for the transition to the aforementioned automated library retrieval system and in terms of the regular practice of stocktake was a widely lauded benefit of RFID that comprised many of the responses to the 'original rationale' question.

- RFID was briefly noted as a cost saving measure and a control against theft, nonreturns and misfiling of library items.

- The ability for clients to the browse the open shelves and have the opportunity for serendipitous discovery is a delightful way to finding interesting resources. Clients derive satisfaction from such an experience and therefore it was necessary not to lose this discovery experience in the new system. Two respondents emphasized the need to enhance the library's discovery systems so it is easy to get a specific item when the clients want it but also to browse and stumble upon interesting or useful resources when not quite sure they need. In response to this, the library has attempted an online mimesis of the serendipitous experience clients may lose without the physical browsing experience through an improved virtual browsing capacity for users searching the online catalogue.

- The issue of clients' concern over the storage of personal information in the tags was raised and with that there was a need to assure clients that only information that will identify a library item and loan rules that apply to that item will be stored.

\section{Processes}

Respondents were eager to speak of the processes involved in the change management process of RFID implementation in two distinct forms; firstly, the processes involved in the implementation (logistics) and secondly the processes resultant from the implementation itself.

To draw from Figure 2 above, the processes involved in the implementation were varied: the selection of an outside supplier, the receipt, encoding and implementation (deployment) of the physical RFID tags, the installation of appropriate check-out and security systems for the best practice of RFID technology, and the education of staff in RFID technology to allow for minimally disruptive service when installed.

The processes resultant from the implementation were noted continually through the interviews as divergent from the projected outcomes both by the outside supplier in their tender to the university to work on the project and in terms of the projected outcomes of RFID technology as a whole. Expectations were, to various degrees, altered with each technological barrier involved in the implementation of the technology, with various respondents noting when prompted on what they would do differently that they would have made several conscious decisions to protect against some of these issues.

\section{Technology}

The RFID project is the beginning of new wave of technological transformation that the library will experience in the coming years. As a university in the heart of Sydney city, space is at a premium. The Library's LRS (Library Retrieval System) is one initiative that will free up space to meet the study space requirements of the increasing student body. The LRS will connect to a new library (in the initial planning stages) and is situated underground consisting of six 15-metre high robotic cranes that operate bins filled with books. Items will be stored in 
bins based on their spine heights. When an item is being stored or retrieved, the bins will be transported by cranes moving up and down the aisles to be retrieved and returned by staff at a picking station. This technological change that is happening in libraries around the world is transforming the way those sources of information are being used. No longer are libraries only book repositories, filled with stacks floor to ceiling and shelves that shroud most of the library floor. This new 'Library of the Future' is expected to be operational from between 2018 to 2019 and expected to create a new environment that is people-centred rather than book-centred. The LRS frees up space which will allow for more interactive learning environments where students can work more collaboratively in the library, for example, mixed media spaces for video editing and production.

\section{Insert Figure 3.}

The LRS has many benefits for collection preservation, client service and sustainability. The LRS stores items in stable temperature and humidity conditions that is ideally suited for preserving paper materials (especially aged items) as opposed to storing items in open shelving where these conditions cannot be achieved. It is also much faster to find items stored in the LRS than on open shelves and so the technology provides efficiency gains.

The UTS LRS is the first academic library retrieval system in the world to integrate RFID technology to this extent. It integrates radio frequency identification technology where each item is tagged with a unique identifier so that it can be tracked for retrieval. RFID acts as a link between the warehouse management system for the LRS and the library catalogue. The other added advantage is that many items can be scanned at a time using RFID in comparison to barcodes which allow only one item to be scanned at a time. In the new library, which is currently in the planning stage, students will be able to request an item in the underground storage facility via the library catalogue and have it delivered to a library service desk within 15 minutes. One respondent signalled further development in the form of a second phase:

'In the second phase of RFID we want to be able to be a bit cleverer in tracking where books have been used, how they move around campus. Previously, we didn't have the capacity to collect data on how those books were being used. With RFID, we can more easily collect data by quickly scanning a run of books that have been retrieved on a trolley or by having a smart shelf on the trolley. That could collect data like, for example, all the science books are on the fifth floor but they are always used on the third floor. It tells us where science people want to study. So having that data helps us design the new library. RFID enables that as it allows us to do that data collection.'

\section{The Impact of Technology on People and Processes}

The implementation of RFID was widely acknowledged among interview respondents to be a costly undertaking, both in terms of financial cost and in terms of organisation, planning, and labour necessary for successful deployment of the technology with minimal interference with library patrons. Notably, the process of tagging artefacts in the library collection had to be both planned and undertaken by library staff and this involved a significant expenditure of labour as well as training in new technology. While one respondent recollected the pressure for this procedure - the tagging - to be done with minimal mistakes, interferences, and waste, they also noted the benefits of the undertaking for the future.

'We're still getting new material, we're still keeping up to date... it's a continuous cycle... hopefully it gave us a good process as well, for the future.' 
The actual implementation of the RFID technology within the context of an academic library proved problematic in that it involved a certain degree of self-managed customisation.

Respondents involved in the planning and implementation stages consistently referred to the specific needs of the UTS Library; another respondent noted the high volume demands of a university library in comparison to past sites of RFID implementation, e.g. public libraries.

Whether due to the need for indigenising the RFID technology into the university library environment or due to the unforeseen time expenditure in tagging and other technological implementation stages, multiple respondents noted a delay in deployment. There was a consistent focus on being 'realistic' and applying 'realistic time-frames' to projects as well as the pressure involved on having such a 'tight period to deliver'. The unforeseen length of time necessary for the implementation of the project was compounded by the relative youth of the technology and thus of the vendor, with multiple respondents noting an insufficient level of support for the breadth of projects that the vendor was actually working on. This, combined with the very tight deadlines the deployment of the project was operating under, resulted in frustration with the level of support given.

\section{Lessons Learned and Visions for the Future}

As with other technological developments, the chronology of RFID will not end after implementation as such respondents were canvassed for their visions of the future of RFID in the context of the Library and the wider implications of the technology for the University beyond the Library, the national and international community. Interestingly one respondent pointed out:

\section{'You can't really do something and not think about the future.'}

The lessons learned from this project were a source of valuable knowledge not just for UTS but for other academic libraries when adopting RFID. A common theme that emerged from the interviews was how the initial project's aim morphed from operational efficiencies alone to operational efficiencies as well as a strategic investment in terms of aligning with all other projects that the Library were carrying out. As a result, the library had to adopt an integrated approach of making this project part of the bigger picture the library was heading toward in the future- known as "Library of the Future" movement at UTS. It was no more an operational intervention but incorporated into the overall Library strategy, in what seems to be an emergent strategy (Mintzberg, 1985) approach.

The respondents with technical responsibilities emphasised the need to anticipate and manage risks. Several risk sources were identified. As a pioneer among academic libraries in Australia in implementing this technology, UTS did not have the luxury of being able to consult other university libraries for "lessons learned" in the Australian context. This risk was rated high as it could have significant cost blow-out implications. Along with this was the question of vendor experience in academic libraries. This was another risk factor as UTS would be the first site of implementation in an academic library. One risk would be costly indigenisation or customisation of standard technology to suit the academic context. UTS' technical staff had to work on a number of customisation initiatives. However, not all universities may have the high calibre technical staff required for this to happen, meaning more costs in securing outsourced technical assistance. As one respondent believes that the vendor and the technical staff of the university must have the mindset of a start-up venture where both are exploring new options to serve the particular needs of an academic library. Another respondent aptly put it: 
'The key here is to take a vendor based turn-key solution and turn it in an in-house capability.

Fortunately, for UTS this did happen because of capable people working together on both sides. Generally, technical staff respondents pointed out that planning, prioritisation, technical integration, understanding impacts and future implications were essential in mitigating risks and were seen as key success factors.

The implementation of RFID in the UTS Library has become a story not merely of technological implementation and the associated change management process, but also a narrative of how technology can be indigenised (customised to suit an academic library) for new and evolving environments. The indigenisation of the technology by using library's own technical expertise demonstrates the emergence of a new reality - the need to innovate by modifying the technology to suit the operations of the library. While their narratives to some degree converged on issues of vendor support, timelines and outcomes, different (or multiple) realities emerged in their own 'timelines' of the project. Multiple realities emerge as a result of the cause and effect of the factors at play as illustrated in Figure 4 below.

\section{Insert Figure 4.}

With the aforementioned development of the innovative LRS, the academic library that RFID has been implemented into is developing and changing into a system that requires more efficient information management and data organisation technology than ever before.

This can be seen in the flexible role the technology can be seen to play in the transfer, set-up and function of the LRS. Aside from the indexing and data management that will benefit the underground storage system, RFID also serves a significant purpose in determining the needs of university library patrons for the design of the new library. The University also plans for this technology to collect and analyse data to help design its new Library.

By tracking the location of items using RFID, it becomes easier to appreciate how students make use of the Library's collection and where they are most likely to browse books. One respondent spoke of how the introduction of RFID had spin off effects on other business units of the university, for example Information Technology Division were looking at applying RFID technology to track their computer equipment and accessories and to integrate the data with a new electronic register that would constantly track movement, generate usage data and assist in stock takes. The use of RFID could become pervasive as confidence and capabilities are built within the organisation. However, the respondent also emphasised that the key is indigenisation - knowing how to domesticate the technology and looking for in-house specific uses.

\section{Conclusion}

In order to transform the UTS library to meet the needs of its customers' expectations for speed and ease of use in the twenty-first century, RFID technology was introduced as the basis of this change process. The combination of innovative collections technology in the form of the Library Retrieval System (LRS) with RFID as a data management system meant that the process of implementation was complicated by a persistent need to indigenise technology for the specific needs of the UTS Library. The original project objectives were derived from RFID implementations in the public library environment. They were transformed significantly during the implementation of the technology in an academic library. As the technology and its practical objectives transformed and changed throughout the 
project, the expectations and objectives of staff within the Library developed accordingly. The complex needs of an academic library, such as high volume, time constraints and specific supply chain management needs created challenges in integration and adaption of the new technology for existing and developing supply chain management processes in the UTS Library system. Ultimately, through the complex interplay of people, processes and technology, the application of RFID in the UTS Library has taken on individual characteristics enabling for improved efficiency for people and processes. The application of RFID in innovative, imaginative ways developed supply chain management and process efficiency, as well as customer service improvements, within the Library as it strives towards flexibility and efficiency, a step towards becoming a library for the future. 


\section{References}

Azevedo, S. G., \& Carvalho, H. 2012. "Contribution of RFID Technology to Better Management of Fashion Supply Chains." International Journal of Retail \& Distribution Management, 40 (2), 128-156.

Bahri, S. \& Ibrahim, A. 2013. "RFID in Libraries: A Case Study on Implementation." Library Hi Tech News, 30, 21-26.

Bhattacharya, M., Chu, C. H., \& Mullen, T. 2007, "RFID Implementation in Retail Industry: Current Status, Issues, and Challenges." In Proceedings of 38th Annual Meeting of the Decision Sciences Institute, Curran Associates: USA, pp. 2171-2176 .

Butters, A. 2008. "RFID in Australian academic libraries: Exploring the barriers to implementation.” Australian Academic \& Research Libraries, 39 (3), 198-206.

Bahri, S., \& Ibrahim, A. 2013. "RFID in libraries: a case study on implementation." Library Hi Tech News, 30 (5), 21-26.

Caldwell-Stone, D. 2010. "Chapter 6: RFID in Libraries.” Library Technology Reports, 46 (8), 38-44.

Chen, J. C., Cheng, C.-H. \& Huang, P. B. 2013. "Supply chain management with lean production and RFID application: A case study". Expert systems with applications, 40, 33893397.

Davey, S. M. B., Michae; Meenan, Brian J; Mcadam, R. 2011. “A Framework to Manage the Early Value Proposition of Emerging Healthcare Technologies." Irish Journal of Management, 31 (1).

Denzin, N. K. \& Lincoln, Y.S. (Eds). 2005. The Sage handbook of Qualitative Research. London: Sage.

Dewi, L. P., Gunawan, I. \& Winoto, C. 2014. "Risk Assessment in Securing Radio Frequency Identification RFID Systems: A Case Study on Petra Christian University Library.” Jurnal Teknologi, 68 .

Edwards, J. 2011. “A Process View of Knowledge Management: It Ain't What You Do, It's the Way that You Do it." Electronic Journal of Knowledge Management, 9 (4).

Ferguson, S., Thornley, C. V., \& Gibb, F. 2013 . "How do libraries manage the ethical and privacy issues of RFID implementation? A qualitative investigation into the decision-making processes of ten libraries." Journal of Librarianship and Information Science, 0961000613518572. doi: 10.1177/0961000613518572

Fluss, D. 2005 . The Real-Time Contact Center: Strategies, Tactics, and Technologies for Building a Profitable Service and Sales Operation, New York: AMACOM.

Heisley, D. D. \& Levy, S. J. 1991. “Autodriving: A Photoelicitation Technique.” Journal of Consumer Research, 18 (3), 257-272

Hellström, D., \& Wiberg, M. 2010. "Improving inventory accuracy using RFID technology: a case study." Assembly Automation, 30 (4), 345-351. 
Hong, I., Dang, J.-F., Tsai, Y.-H., Liu, C.-S., Lee, W.-T., Wang, M.-L. \& Chen, P.-C. 2011. "An RFID application in the food supply chain: a case study of convenience stores in Taiwan." Journal of Food Engineering, 106, 119-126.

Jain, P. \& Sharma, P. 2014. "RFID Technology Implementation: A Case Study of Institute of Home Economics." Paper presented at the Content to Connectivity: Paradigm Shifts in Knowledge, Innovation, Information Representation, Information Management Systems and Librarianship, Tecina, April 11-12.

Mahajan, P. \& Singh, N. K. 2014. "RFID and It's Use in Libraries: A Literature Review." International Journal of Information Dissemination and Technology, 4, 117-123.

Makori, E. O. 2013. "Adoption of Radio Frequency Identification Technology in University Libraries: A Kenyan perspective.” Electronic Library, The, 31, 208-216.

Mehrjerdi, Y. Z. 2011. "RFID: The Big Player in Libraries of the Future." The Electronic Library, 29 (1), 36-51.

Mintzberg, H. W., J.A. 1985. “Of Strategies, Deliberate and Emergent.” Strategic Management Journal, 6 (3): 257-272.

Molnar, D., \& Wagner, D. 2004. "Privacy and security in library RFID: issues, practices, and architectures." Paper presented at the $11^{\text {th }}$ ACM Conference on Computer and Communications Security, Washington, October 25-29.

Norwood J. \& Skinner, B. 2012. "Implementing RFID in a hospital library: A Scoping Study." Health Information \& Libraries Journal, 29, 162-165.

OECD. 2008. OECD Policy Guidance: A Focus on Information Security and Privacy Applications, Impacts and Country Initiatives, Seoul: OECD.

Satoglu, S.I., Ustundag, A. and Kilinc, M.S. 2013. "Value of RFID in Library Management System." In The Value of RFID, edited by Alp Ustundag, 155-167. London:Springer.

Shahid, S. M. 2005. "Use of RFID technology in libraries: a new approach to circulation, tracking, inventorying, and security of library materials." Library Philosophy and Practice ejournal, 62.

Siguenza-Guzman, L., Van Den Abbeele, A. \& Cattrysse, D. 2014. "Time-Driven ActivityBased Costing Systems for Cataloguing Processes: A Case Study." The Liber Quarterly, 84 (1), 76-98.

Sing, J., Brar, N. \& Fong, C. 2013. "The State of RFID Applications in libraries." Information technology and libraries, 25, 24-32.

Smith, D. 2014. "Leadership in academic and public libraries: A time of change." The Australian Library Journal, 63, 259-259.

Southard, P. B., Chandra, C. \& Kumar, S. 2012. "RFID in healthcare: a Six Sigma DMAIC and simulation case study." International journal of health care quality assurance, 25, 291321. 
Sugie, N. 2013. "Application of radio frequency identification technology for the study of information-seeking behavior of public library users: Preliminary Analysis." Library \& Information Science Research, 35 (1), 69-77.

Want, R. 2006. "An introduction to RFID technology." Pervasive Computing, IEEE, 5 1 , 2533.

Williams, D. E. \& Leask, Jay. 2011. "People, Process, Technology Strategy for Enterprise 2.0." Accessed August 3. http://www.boozallen.com/media/file/People-Process-TechnologyEnterprise2.pdf

Wyld, D. C. 2006. "RFID 101: the next big thing for management." Management Research News, 29 (4), 154-173.

Yu, S.C. 2007. "RFID implementation and benefits in libraries." Electronic Library, The, 25 (1), 54-64.

Yin, R. K. 2014. Case study research: Design and methods, London: Sage. 